\title{
EFFECTS OF TEMPERATURE, FOOD CONCENTRATION, AND INITIAL ROTIFER DENSITY ON THE INTERSPECIFIC COMPETITION BETWEEN TWO ROTIFER SPECIES
}

\author{
GAO, Y. ${ }^{1,2}-$ LIU, Q. F. ${ }^{1,2^{*}}-$ ZHENG, Y. T. ${ }^{1,2,3}-$ LAI, Z. N. ${ }^{1,2}-$ WANG, C. ${ }^{1,2}-$ ZENG, Y. Y. ${ }^{1,2}-$ \\ YANG, W. L. ${ }^{1,2}$ \\ ${ }^{1}$ Pearl River Fisheries Research Institute, Chinese Academy of Fishery Sciences, Guangzhou \\ 510380, China \\ (e-mail: gaoyuan0328@163.com; phone: +86-186-2046-0628; fax: +86-20-8161-6162-Y. Gao) \\ ${ }^{2}$ Key Laboratory of Aquatic Animal Immune Technology of Guangdong Province, Guangzhou \\ 510380, China \\ ${ }^{3}$ Zhongkai University of Agriculture and Engineering, Guangzhou 510225, China \\ *Corresponding author \\ e-mail: liuqfwh@163.com; phone: +86-134-2752-1580; fax: +86-20-8161-6162 \\ (Received $1^{\text {st }}$ Jun 2021; accepted $3^{\text {rd }}$ Sep 2021)
}

\begin{abstract}
There is often intense competition among species in an environment with limited resources and space, leading to the exclusion of inferior competitors, reduced species diversity, and changes in zooplankton communities. This study investigated the interspecific competition between two dominant rotifer species in the Pearl River Basin, Brachionus calyciflorus and Keratella valga, through laboratory experiments at different temperatures, food concentrations, and initial rotifer densities. In separate cultures, the population growth of both rotifer species was affected by changes in temperature, food density, and initial density. In mixed cultures, B. calyciflorus was inhibited by competition, leading to an overall decrease in its population growth rate and maximum population density. K. valga was also affected by competition, leading to an increase in its population growth rate and maximum population density at $20^{\circ} \mathrm{C}$ or at an initial density of $1.0 \times 10^{6}$ cells $/ \mathrm{mL}$. B. calyciflorus was excluded by $K$. valga at low and medium food concentrations $\left(0.5 \times 10^{6}\right.$ and $1.0 \times 10^{6}$ cells $\left./ \mathrm{mL}\right)$, whereas the opposite was found at high food concentration $\left(3.0 \times 10^{6}\right.$ cells $\left./ \mathrm{mL}\right)$. Food concentration is obviously the main factor affecting outcome. Temperature, initial density, and interactions between the three factors also have an effect on it.
\end{abstract}

Keywords: Brachionus calyciflorus, Keratella valga, species diversity, population growth rate, maximum population density

\section{Introduction}

Zooplankton is an important component that plays a key connecting role in the aquatic food chain. Rotifers are one of the important groups of zooplankton widely distributed worldwide. They reproduce rapidly and have a short life cycle. They are not only important for the structure and function of the aquatic ecosystem, but are also meaningful to aquaculture feed science. They can also be used as a test organism for environmental monitoring and ecotoxicology research worldwide (Van Dijk and Van Zanten, 1995; Devetter, 1998; Andrzej and Jolanta, 2005).

Competition among rotifer species is influenced by various factors such as body size, feeding habits, food type and nutritional quality, temperature, salinity, food level, inoculation density and diapause (Fernández-Araiza et al., 2005; Montero-Pau and Serra, 2011; Divya et al., 2012; Li and Niu, 2015; Rebolledo et al., 2018; Zhang et al., 2019). 
The outcome of rotifer population competition is ultimately related to population growth and reproduction; whereas the outcome of interspecific competition is the change in the community structure of the rotifer population. The experimental results of Wang et al. (2014) showed that temperature significantly affected the population parameters of Brachionus calyciflorus. The most suitable temperature for the growth of B. calyciflorus is $28-32^{\circ} \mathrm{C}$, and the highest temperature should not exceed $40{ }^{\circ} \mathrm{C}$ (Wang, 1995). Many studies have confirmed that the seasonal changes of rotifer population distribution and the spatiotemporal dynamics of its community structure are largely affected by temperature (Ruttner-Kolisko, 1974; May, 1983; Huang et al., 1985; Herzig, 1987; Arora, 2003; Wen et al., 2004). Zooplankton can quickly detect slight changes in temperature (Benincà et al., 2011). Different plankton species have different sensitivity to temperature. Therefore, the outcome of population competition is likely to vary with temperature (Feniova et al., 2011).

Rotifers feed on algae and protozoa for population growth and reproduction. Thus, there will inevitably be interspecific or intraspecific competition of rotifers when food is insufficient. Therefore, food has a significant impact on the population growth rate and density of rotifers (Zhang et al., 2005; Tian et al., 2009; Ma et al., 2004; Dong et al., 2004). The number and diversity of zooplankton populations and the outcome of interspecific competition are largely restricted by food factors (Sterner and Hessen, 1994; Elser et al., 2001; Ferrao-Filho et al., 2003; Persson et al., 2008; EspinosaRodríguez et al.,2012). The change in competition outcome will change the rotifer community structure and population density. In short, food resources affect the community structure and population changes of rotifers (Yoshida, 2003; Aoyagui and Bonecker, 2005; Lin et al., 2005). Interspecific competition of rotifers often leads to a decrease in the population growth rate of competitors, but the degree of decrease changes with food density. When food availability meets competition demands, the population growth rates of competitors play a huge role in the outcome of interspecific competition. Species with low population growth rates are usually at a disadvantage in the interspecific competition. However, the population growth rate does not fully represent the interspecific competitiveness of a competitor. Reproductive capacity under extremely low food density plays a more decisive role (Stemberger and Gilbert, 1985). Therefore, rotifers with higher population growth rates are likely to gain growth advantages when food is scarce (Stemberger and Gilbert, 1987).

Many studies have shown that the growth and reproduction of rotifers are largely affected by it (Xi et al., 2000a; Zhang et al., 2005; Tian et al., 2009). Therefore, the competitiveness of rotifers must be closely related to the initial density. When there is a very large difference in the competitive capacity of competitors, the competitor with a greater competitive capacity will inevitably gain an advantage in the competition. However, when the difference is small, the initial density of competitors will play a crucial role.

Food levels may modify the outcome of competition between two rotifer species which differ widely in their growth rates. When two species of rotifers compete for limited food, normally the one with higher population growth rate may be expected to outcompete the other with lower growth rate (Rothhaupt, 1990). However, this does not appear to hold true for many species (Sarma et al., 1996, 2007; Sarma and Nandini, 2002; Divya et al., 2012). Xi et al. (2019) studied the relationship between the results of competition and their population growth rate for Brachionus angularis and $B$. calyciflorus when they competed for limited food resources. 
B. calyciflorus and Keratella valga are the dominant rotifer species in the Pearl River Basin. However, there is no report on the interspecific competition between the two rotifer species. This study is the first to investigate the interspecific competition between $B$. calyciflorus and $K$. valga at different temperatures, food concentrations, and initial densities. It aims to better understand the competitive relationship between freshwater rotifers and reveal the effects of temperature, food, and initial density on the community structure of freshwater planktonic rotifers in the Pearl River Basin. The results have important theoretical implications for understanding the interspecific competition and community structure and function of zooplankton.

\section{Materials and methods}

\section{Source and culture of the two rotifer species}

B. calyciflorus was purchased from Qianjiangshui Water Biotechnology Co., Ltd.

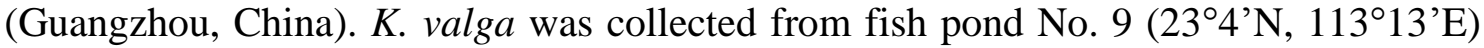
of Pearl River Fisheries Research Institute, Chinese Academy of Fishery Sciences. The two rotifer species were incubated in EPA medium in a constant temperature incubator at $25 \pm 1{ }^{\circ} \mathrm{C}$ under natural light and fed every $24 \mathrm{~h}$ with $S$. obliquus cultivated in BG11 medium and in exponential growth period (at a feeding density of $0.5 \times 10^{6}, 1.0 \times 10^{6}$, or $3.0 \times 10^{6}$ cells $/ \mathrm{mL}$ according to preculture conditions) for clonal culture. Before the start of the competition experiments, the two rotifer species were pre-cultured for more than $48 \mathrm{~h}$ by feeding with $S$. obliquus at $0.5 \times 10^{6}, 1.0 \times 10^{6}$ and $3.0 \times 10^{6}$ cells $/ \mathrm{mL}$, respectively, in a constant temperature incubator under natural light at $20 \pm 1,25 \pm 1$, and $30 \pm 1{ }^{\circ} \mathrm{C}$.

For the preparation of EPA medium, $0.096 \mathrm{~g}$ of sodium bicarbonate, $0.06 \mathrm{~g}$ of calcium sulfate, $0.06 \mathrm{~g}$ of magnesium sulfate, and $0.004 \mathrm{~g}$ of calcium chloride were weighed using an analytical balance and transferred to a $1000-\mathrm{mL}$ beaker. Next, $1000 \mathrm{~mL}$ of deionized water was added with stirring using a glass rod to achieve full dissolution (U.S. EPA, 1985).

\section{Equipment}

The equipment used in the experiments are shown in Table 1.

Table 1. Equipment

\begin{tabular}{|c|c|c|}
\hline Equipment & Model/specification & Manufacturer \\
\hline Analytical balance & FB2004A & Jinghong Experimental Equipment Co., Ltd. (Shanghai, China) \\
\hline Pen-type $\mathrm{pH}$ meter & PH-902 & Sierte Electromechanical Equipment Co., Ltd. (Changzhou, China) \\
\hline Plankton net & No. 25 trawl-type & Dengxun Instrument Equipment Co., Ltd. (Xiamen, China) \\
\hline Intelligent light incubator & MGC-250BP-2 & Yiheng Technology Co., Ltd. (Shanghai, China) \\
\hline Biomicroscope & BX53 & Olympus Corporation (Beijing, China) \\
\hline High-speed centrifuge & $10-1000 \mu \mathrm{L} ; 1000-5000 \mu \mathrm{L}$ & Pingfan Instrument Co., Ltd. (Changsha, China) \\
\hline Single-channel manual pipette & $2-10 \mathrm{~mL}$ & Gaoxin Chemical Glass Instrument Co., Ltd. (Shanghai, China) \\
\hline Pipette tip & $1 \mathrm{~mL}, 5 \mathrm{~mL}, 10 \mathrm{~mL}$ & Labgic Technology Co., Ltd. (Beijing, China) \\
\hline Beaker & $25 \mathrm{~mL}, 1000 \mathrm{~mL}$ & Leigu Instrument Co., Ltd. (Shanghai, China) \\
\hline Erlenmeyer flask & $500 \mathrm{~mL}$ & Leigu Instrument Co., Ltd. (Shanghai, China) \\
\hline Plankton counting chamber & $1 \mathrm{~mL}$ & Purity Instrument Co., Ltd. (Beijing, China) \\
\hline
\end{tabular}




\section{Reagents}

The reagents used in the experiments are shown in Table 2.

Table 2. Reagents

\begin{tabular}{|c|c|c|c|c|}
\hline Reagent & Chemical formula & $\begin{array}{c}\text { Molecular } \\
\text { weight }\end{array}$ & Grade & Source \\
\hline Sodium bicarbonate & $\mathrm{NaHCO}_{3}$ & 84.01 & AR & $\begin{array}{l}\text { Sinopharm Chemical Reagent Co., Ltd. } \\
\text { (Shanghai, China) }\end{array}$ \\
\hline Calcium sulfate & $\mathrm{CaSO}_{4}$ & 172.17 & $\mathrm{AR}$ & $\begin{array}{l}\text { Sinopharm Chemical Reagent Co., Ltd. } \\
\text { (Shanghai, China) }\end{array}$ \\
\hline Magnesium sulfate & $\mathrm{MgSO}_{4}$ & 120.37 & AR & $\begin{array}{c}\text { Aladdin Biochemical Technology Co., } \\
\text { Ltd. (Shanghai, China) }\end{array}$ \\
\hline Potassium Chloride & $\mathrm{KCl}$ & 74.55 & AR & $\begin{array}{l}\text { Sinopharm Chemical Reagent Co., Ltd. } \\
\text { (Shanghai, China) }\end{array}$ \\
\hline Sodium nitrate & $\mathrm{NaNO}_{3}$ & 84.99 & AR & $\begin{array}{l}\text { Sigma-Aldrich Trading Co., Ltd. } \\
\text { (Shanghai, China) }\end{array}$ \\
\hline Dipotassium phosphate & $\mathrm{K}_{2} \mathrm{HPO}_{4}$ & 174.18 & $\mathrm{AR}$ & $\begin{array}{c}\text { Aladdin Biochemical Technology Co., } \\
\text { Ltd. (Shanghai, China) }\end{array}$ \\
\hline Magnesium sulfate heptahydrate & $\mathrm{MgSO}_{4} \cdot 7 \mathrm{H}_{2} \mathrm{O}$ & 246.47 & $\mathrm{AR}$ & $\begin{array}{c}\text { Aladdin Biochemical Technology Co., } \\
\text { Ltd. (Shanghai, China) }\end{array}$ \\
\hline Calcium chloride heptahydrate & $\mathrm{CaCl}_{2} \cdot 7 \mathrm{H}_{2} \mathrm{O}$ & 237.11 & $\mathrm{AR}$ & $\begin{array}{l}\text { Sinopharm Chemical Reagent Co., Ltd. } \\
\text { (Shanghai, China) }\end{array}$ \\
\hline Citric acid & $\mathrm{C}_{6} \mathrm{H}_{8} \mathrm{O}_{7}$ & 192.13 & AR & $\begin{array}{l}\text { HWRK Chem Co., Ltd. (Beijing, } \\
\text { China) }\end{array}$ \\
\hline Ferric ammonium citrate & $\mathrm{C}_{6} \mathrm{H}_{8} \mathrm{FeNO}_{7}$ & 261.98 & $\mathrm{AR}$ & $\begin{array}{c}\text { Aladdin Biochemical Technology Co., } \\
\text { Ltd. (Shanghai, China) }\end{array}$ \\
\hline $\begin{array}{l}\text { Ethylenediaminetetraacetic acid } \\
\text { disodium salt dihydrate }\end{array}$ & $\mathrm{EDTANa}_{2}$ & 336.21 & $\mathrm{AR}$ & $\begin{array}{c}\text { Aladdin Biochemical Technology Co., } \\
\text { Ltd. (Shanghai, China) }\end{array}$ \\
\hline Sodium carbonate & $\mathrm{Na}_{2} \mathrm{CO}_{3}$ & 105.99 & $\mathrm{AR}$ & $\begin{array}{c}\text { Aladdin Biochemical Technology Co., } \\
\text { Ltd. (Shanghai, China) }\end{array}$ \\
\hline Boric acid & $\mathrm{H}_{3} \mathrm{BO} 3$ & 61.8 & $\mathrm{AR}$ & $\begin{array}{c}\text { Sinopharm Chemical Reagent Co., Ltd. } \\
\text { (Shanghai, China) }\end{array}$ \\
\hline Manganese chloride tetrahydrate & $\mathrm{MnCl}_{2} \cdot 4 \mathrm{H}_{2} \mathrm{O}$ & 197.91 & $\mathrm{AR}$ & $\begin{array}{c}\text { Aladdin Biochemical Technology Co., } \\
\text { Ltd. (Shanghai, China) }\end{array}$ \\
\hline Zinc sulfate & $\mathrm{ZnSO}_{4}$ & 161.45 & AR & $\begin{array}{c}\text { Aladdin Biochemical Technology Co., } \\
\text { Ltd. (Shanghai, China) }\end{array}$ \\
\hline Sodium manganate & $\mathrm{Na}_{2} \mathrm{MnO}_{4}$ & 164.92 & $\mathrm{AR}$ & $\begin{array}{c}\text { Aladdin Biochemical Technology Co., } \\
\text { Ltd. (Shanghai, China) }\end{array}$ \\
\hline Copper sulfate pentahydrate & $\mathrm{CuSO}_{4} \cdot 5 \mathrm{H}_{2} \mathrm{O}$ & 41.05 & AR & $\begin{array}{c}\text { Aladdin Biochemical Technology Co., } \\
\text { Ltd. (Shanghai, China) }\end{array}$ \\
\hline Cobalt nitrate hexahydrate & $\mathrm{Co}\left(\mathrm{NO}_{3}\right)_{2} \cdot 6 \mathrm{H}_{2} \mathrm{O}$ & 291.03 & AR & $\begin{array}{c}\text { Aladdin Biochemical Technology Co., } \\
\text { Ltd. (Shanghai, China) }\end{array}$ \\
\hline
\end{tabular}

\section{Competition experiments}

Experiments were performed to determine the outcome of the competition between $B$. calyciflorus and $K$. valga under the following conditions:

Experiment 1: at different temperatures and food concentrations at an initial rotifer density of 3 ind./mL.

Experiment 2: at different temperatures and initial rotifer densities (1, 3, and 5 ind. $/ \mathrm{mL}$ ) at a food concentration of $0.5 \times 10^{6}$ cells $/ \mathrm{mL}$.

Experiment 3: at different food concentrations and initial rotifer densities (1, 3, and $5 \mathrm{ind} . / \mathrm{mL}$ ) at a temperature of $25^{\circ} \mathrm{C}$.

In each experiment, separate cultures of B. calyciflorus and $K$. valga were used as the control group, and the mixed cultures of the two rotifer species were used as the competition group. Each experiment was repeated three times. Rotifers for inoculation 
were randomly selected from the culture system in the exponential growth period under the corresponding culture conditions. The experiment was performed with a volume of $20 \mathrm{~mL}$ in a $25-\mathrm{mL}$ beaker. After the start of the experiment, complete counting or three rounds of parallel counting by sampling of $1-3 \mathrm{~mL}$ (depending on the population density) of the separate and mixed rotifer cultures were performed every day. After counting, all surviving animals were transferred back to the original beakers. The competition experiments continued until all animals of one species in the mixed culture system died or until 30-35 days had elapsed.

The experimental culture is shown in Figure 1.

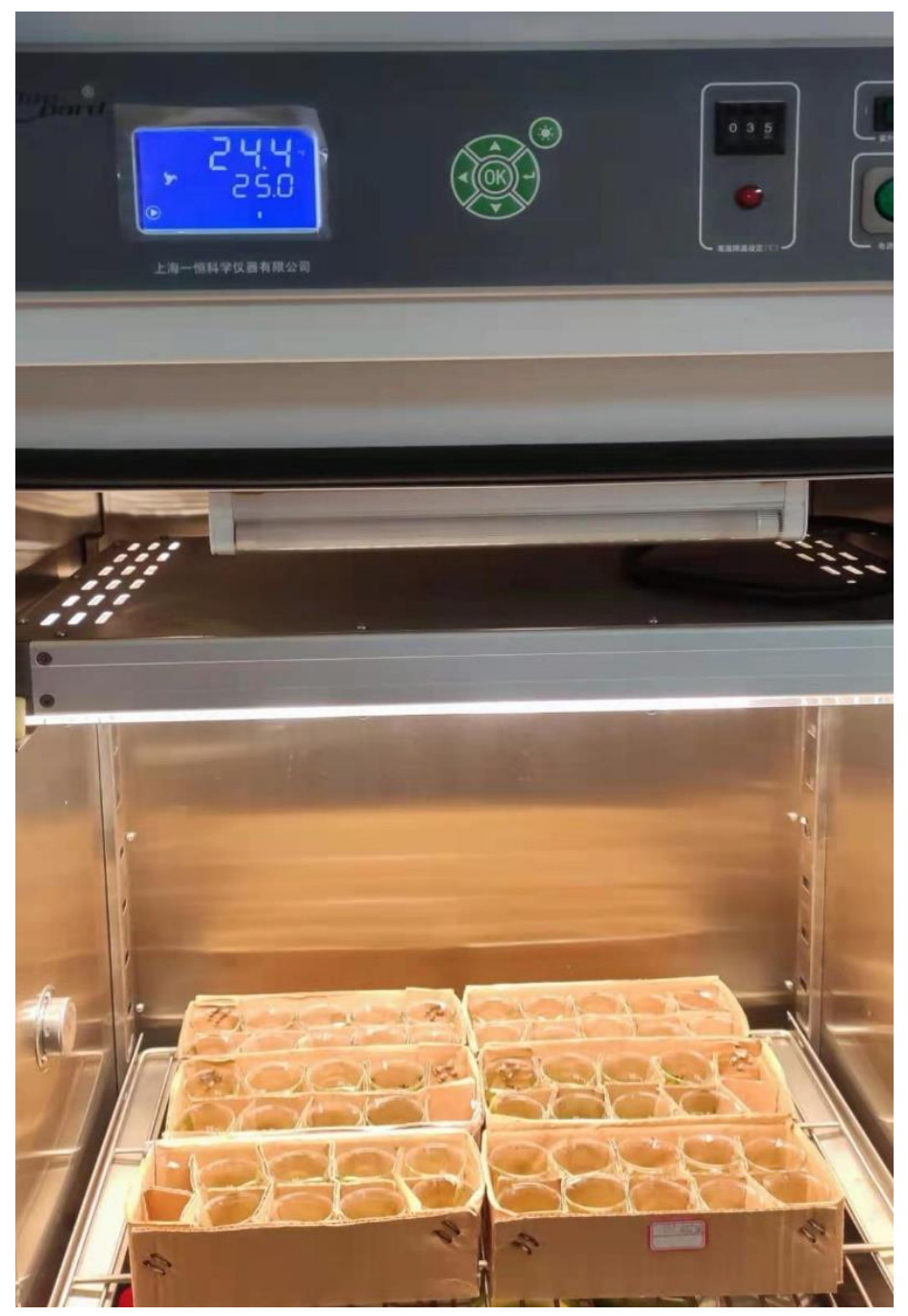

Figure 1. Photo of the experimental culture

\section{Data collection and calculation of rotifer population density}

Data were collected for each experimental group every $24 \mathrm{~h}$ after the start of the experiment. Every day at 9 a.m., after the beakers were shaken, $1 \mathrm{~mL}$ of rotifer culture medium was randomly transferred using a pipette to a 1-mL plankton counting chamber and counted under a biomicroscope to calculate the average population density of rotifers in each group. 


\section{Parameter calculation and curve plotting}

After the end of the experiments, the population growth curves were plotted for each rotifer species under each combination of experimental conditions based on the population densities recorded.

Four to 6 data points during the exponential growth period were selected to calculate the population growth rate for each repetition (Dumont et al., 1995).

The population growth rate was calculated from:

$$
\mathrm{r}=\left(\ln \mathrm{N}_{\mathrm{t}}-\ln \mathrm{N}_{0}\right) / \mathrm{t}
$$

where $\mathrm{N}_{0}$ and $\mathrm{N}_{t}$ are the population densities of rotifers at the beginning of the experiment and on Day t, respectively; and $t$ is the number of days in the experiment.

The histograms of the maximum population densities under each combination of experimental conditions were plotted based on the highest point of the corresponding population growth curve.

\section{Data analysis}

The differences in the population growth rates and maximum population densities of $B$. calyciflorus and $K$. valga were analyzed by three-way analysis of variance and multiple comparisons using SPSS 25.0. Statistical significance was tested at $\alpha=0.05$. T-test was used for mean comparison in this study.

\section{Results and analysis}

\section{Outcome of competition between $B$. calyciflorus and $K$. valga at different temperatures and food concentrations}

The population growth dynamics and outcome of competition between $B$. calyciflorus and $K$. valga at different temperatures and food concentrations are shown in Figure 2.

In general, regardless of competition, the population densities of both $B$. calyciflorus and $K$. valga increased and then decreased with increasing temperature. However, the population densities of both species remained at a relatively stable level of 2 ind./L at $20^{\circ} \mathrm{C}$ and a food concentration of $0.5 \times 10^{6}$ cells $/ \mathrm{mL}$. In mixed cultures, interspecific competition inhibited the population density growth of both species, leading to lower population densities of both species compared to those in separate cultures. However, they promoted the population density growth of each other at the lowest temperature of $20^{\circ} \mathrm{C}$ and food concentrations of $0.5 \times 10^{6}$ and $1.0 \times 10^{6}$ cells $/ \mathrm{mL}$, leading to higher population densities of both species in mixed cultures than in separate cultures.

Regardless of temperature, $B$. calyciflorus was competitively excluded by $K$. valga at lower food concentrations $\left(0.5 \times 10^{6}\right.$ and $1.0 \times 10^{6}$ cells $\left./ \mathrm{mL}\right)$. At the highest food concentration $\left(3.0 \times 10^{6}\right.$ cells $\left./ \mathrm{mL}\right), K$. valga was competitively excluded by $B$. calyciflorus; and the duration of competitive exclusion decreased with increasing temperature and food concentration.

The results of three-way analysis of variance for temperature, food concentration, and competition affecting the population growth rates and maximum population densities of B. calyciflorus and $K$. valga are shown in Table 3. Food concentration had a 
significant effect on the maximum population density of B. calyciflorus $(p<0.05)$, whereas other factors and interactions had no significant effect on the population growth rate or maximum population density of B. calyciflorus $(p>0.05)$. Temperature, food concentration, competition with B. calyciflorus, and their interactions had no significant effect on the population growth rate or maximum population density of $K$. valga $(p>0.05)$.

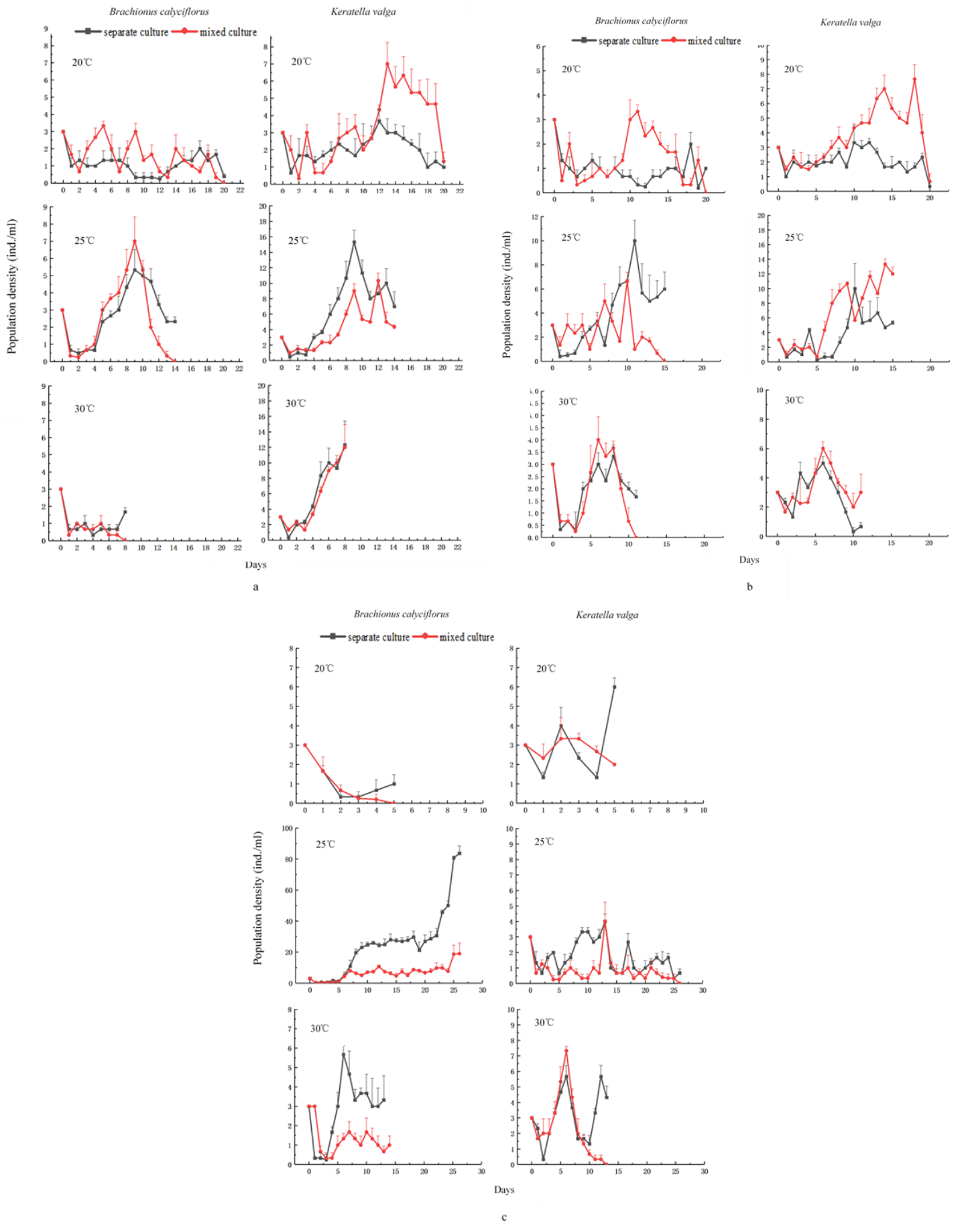

Figure 2. Population growth of B. calyciflorus and K. valga in separate and mixed cultures at different temperatures (mean \pm standard errors) ( a. food concentration $=0.5 \times 10^{6}$ cells $/ \mathrm{mL} ; b$. food concentration $=1.0 \times 10^{6} \mathrm{cells} / \mathrm{mL} ; \mathrm{c}$. food concentration $=3.0 \times 10^{6} \mathrm{cell} / \mathrm{s} / \mathrm{mL}$ ) 
Table 3. Three-way analysis of variance of population growth rates and maximum population densities of B. calyciflorus and $K$. valga ( $p$-value)

\begin{tabular}{c|c|c|c|c|c|c|c|c}
\hline Competitor & Parameter & $\mathbf{T}$ & $\mathbf{F}$ & $\mathbf{C}$ & $\mathbf{T} * \mathbf{F}$ & $\mathbf{T} * \mathbf{C}$ & $\mathbf{F} * \mathbf{C}$ & $\mathbf{T} * \mathbf{F}^{*} \mathbf{C}$ \\
\hline \multirow{2}{*}{ B. calyciflorus } & Population growth rate & 0.106 & 0.361 & 0.544 & 0.553 & 0.586 & 0.976 & 0.229 \\
& Maximum population density & 0.139 & $\mathbf{0 . 0 4 8}$ & 0.530 & 0.143 & 0.976 & 0.752 & 0.796 \\
\hline \multirow{2}{*}{ K. valga } & Population growth rate & 0.475 & 0.316 & 0.914 & 0.675 & 0.526 & 0.919 & 0.534 \\
& Maximum population density & 0.970 & 0.663 & 0.734 & 0.683 & 0.919 & 0.861 & 0.871 \\
\hline
\end{tabular}

T: temperature, F: food concentration, C: competition

Regardless of temperature and food concentration, the competition with $K$. valga inhibited the population growth of $B$. calyciflorus, leading to a decrease in the population growth rate and maximum population density of $B$. calyciflorus. On the other hand, the competition with $B$. calyciflorus promoted the population growth of $K$. valga, leading to a slight increase in the population growth rate and maximum population density of K. valga (Table 3; Fig. 3).
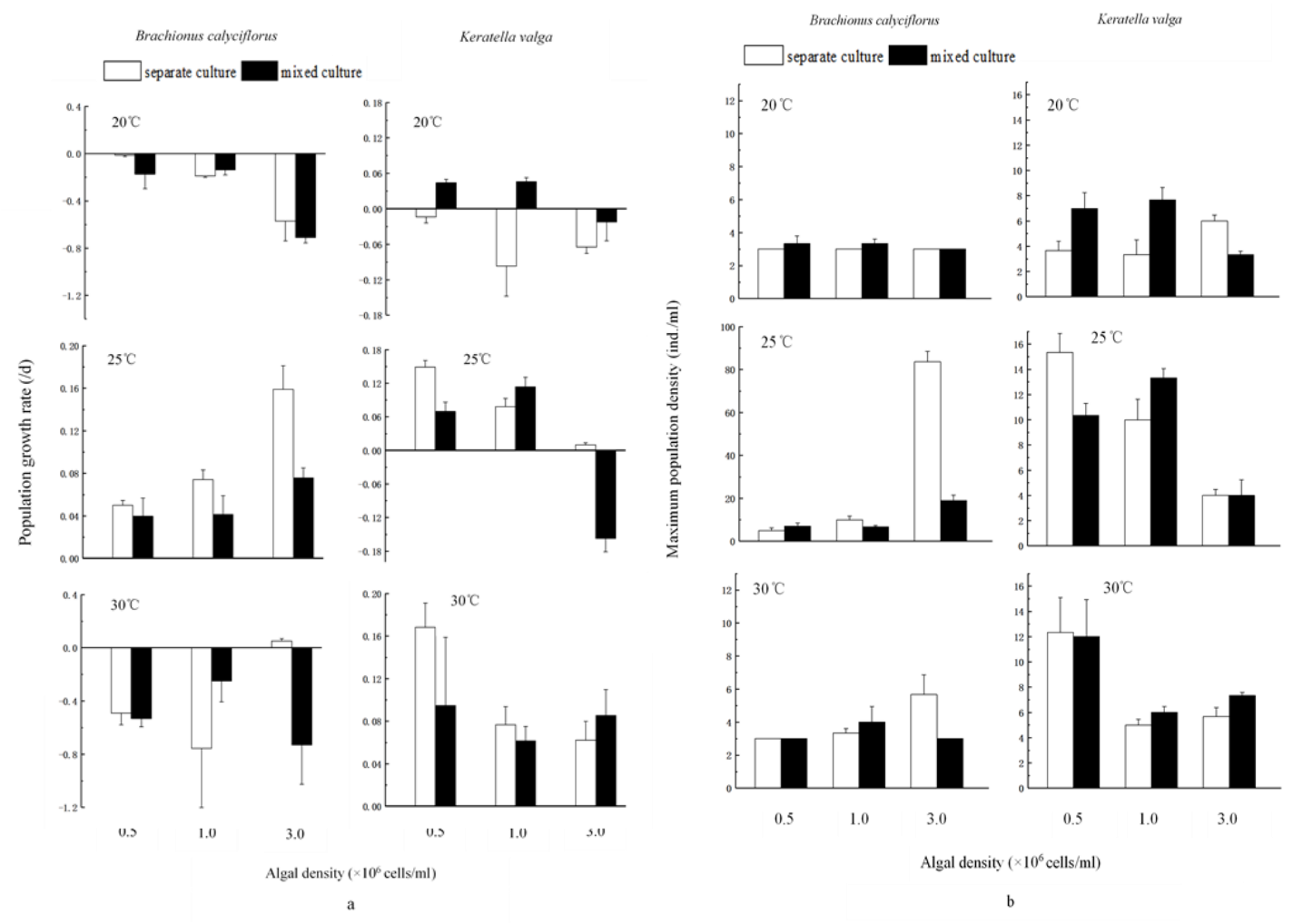

Figure 3. Population growth rates (a) and maximum population densities $(b)$ of B. calyciflorus and $K$. valga in separate and mixed cultures at different temperatures and food concentrations (mean \pm standard errors)

The population growth rates of B. calyciflorus and $K$. valga at different temperatures and food concentrations in separate and mixed cultures are shown in Figure 3a. At any food concentration, the growth rate of $K$. valga increased with increasing temperature. The population growth rate of $B$. calyciflorus was lower in mixed cultures than in separate cultures, and lower than that of $K$. valga in mixed cultures. Regardless of 
competition, the population growth rate of B. calyciflorus was positive at $25{ }^{\circ} \mathrm{C}$ only, and negative at the other two temperatures. At $20^{\circ} \mathrm{C}$, the population growth rate of $K$. valga was higher in mixed cultures than in separate cultures.

The maximum population densities of $B$. calyciflorus and $K$. valga at different temperatures and food concentrations in separate and mixed cultures are shown in Figure $3 b$. Regardless of competition, the maximum population density of $B$. calyciflorus in separate and mixed cultures increased with increasing temperature ( $p<0.05$ ). Regardless of temperature, the maximum population density of $K$. valga was higher than that of B. calyciflorus in mixed cultures.

\section{Outcome of competition between $B$. calyciflorus and $K$. valga at different temperatures and initial densities}

The population growth dynamics and outcome of competition between B. calyciflorus and $K$. valga at different temperatures and initial densities are shown in Figure 4.

In general, regardless of competition, the population densities of B. calyciflorus and $K$. valga increased with increasing initial density, but did not change significantly with increasing temperature. Regardless of initial density and temperature, the competition with $K$. valga inhibited the population growth of $B$. calyciflorus, leading to a decrease in the population density of $B$. calyciflorus in mixed cultures, and eventually competitively eliminating $B$. calyciflorus. Moreover, the duration of competitive exclusion decreased with increasing temperature, and with increasing initial density. On the contrary, the competition with $B$. calyciflorus promoted the population growth of $K$. valga, resulting in significantly higher population densities of $K$. valga in mixed cultures than in separate cultures, except at a temperature of $25^{\circ} \mathrm{C}$ and an initial density of $3 \mathrm{ind} . / \mathrm{mL}$, at which the population density of $K$. valga was lower in mixed cultures than in separate cultures.

The results of three-way analysis of variance for temperature, food concentration, and competition affecting the population growth rates and maximum population densities of $B$. calyciflorus and $K$. valga are shown in Table 4. Temperature, initial density, competition with $K$. valga, and their interactions had no significant effect on the population growth rate or maximum population density of B. calyciflorus $(p>0.05)$. Similarly, temperature, initial density, competition with $B$. calyciflorus, and their interactions had no significant effect on the population growth rate or maximum population density of $K$. valga $(p>0.05)$.

Table 4. Three-way analysis of variance of population growth rates and maximum population densities of B. calyciflorus and K. valga (p-value)

\begin{tabular}{c|c|c|c|c|c|c|c|c}
\hline Competitor & Parameter & T & $\mathbf{I}$ & $\mathbf{C}$ & $\mathbf{T}^{*} \mathbf{I}$ & $\mathbf{T} * \mathbf{C}$ & $\mathbf{I} * \mathbf{C}$ & $\mathbf{T}^{*} \mathbf{I}^{*} \mathbf{C}$ \\
\hline \multirow{2}{*}{ B. calyciflorus } & Population growth rate & 0.114 & 0.224 & 0.573 & 0.317 & 0.786 & 0.883 & 0.974 \\
& Maximum population density & 0.338 & 0.071 & 0.518 & 0.301 & 0.806 & 0.660 & 0.812 \\
\hline \multirow{2}{*}{ K. valga } & Population growth rate & 0.864 & 0.454 & 0.816 & 0.671 & 0.689 & 0.925 & 0.969 \\
& Maximum population density & 1.000 & 0.626 & 0.929 & 0.572 & 0.728 & 0.899 & 0.962 \\
\hline
\end{tabular}

T: temperature, I: initial density, C: competition

Regardless of temperature and initial density, the competition with $K$. valga inhibited the population growth of $B$. calyciflorus, leading to a significant decrease in the population growth rate and a small decrease in the maximum population density of $B$. calyciflorus. When competing B. calyciflorus, the population growth rate and maximum 
population density of $K$. valga increased significantly at $20^{\circ} \mathrm{C}$, and decreased significantly at $25^{\circ} \mathrm{C}$ and $30^{\circ} \mathrm{C}$ (Table 4; Fig. 5).

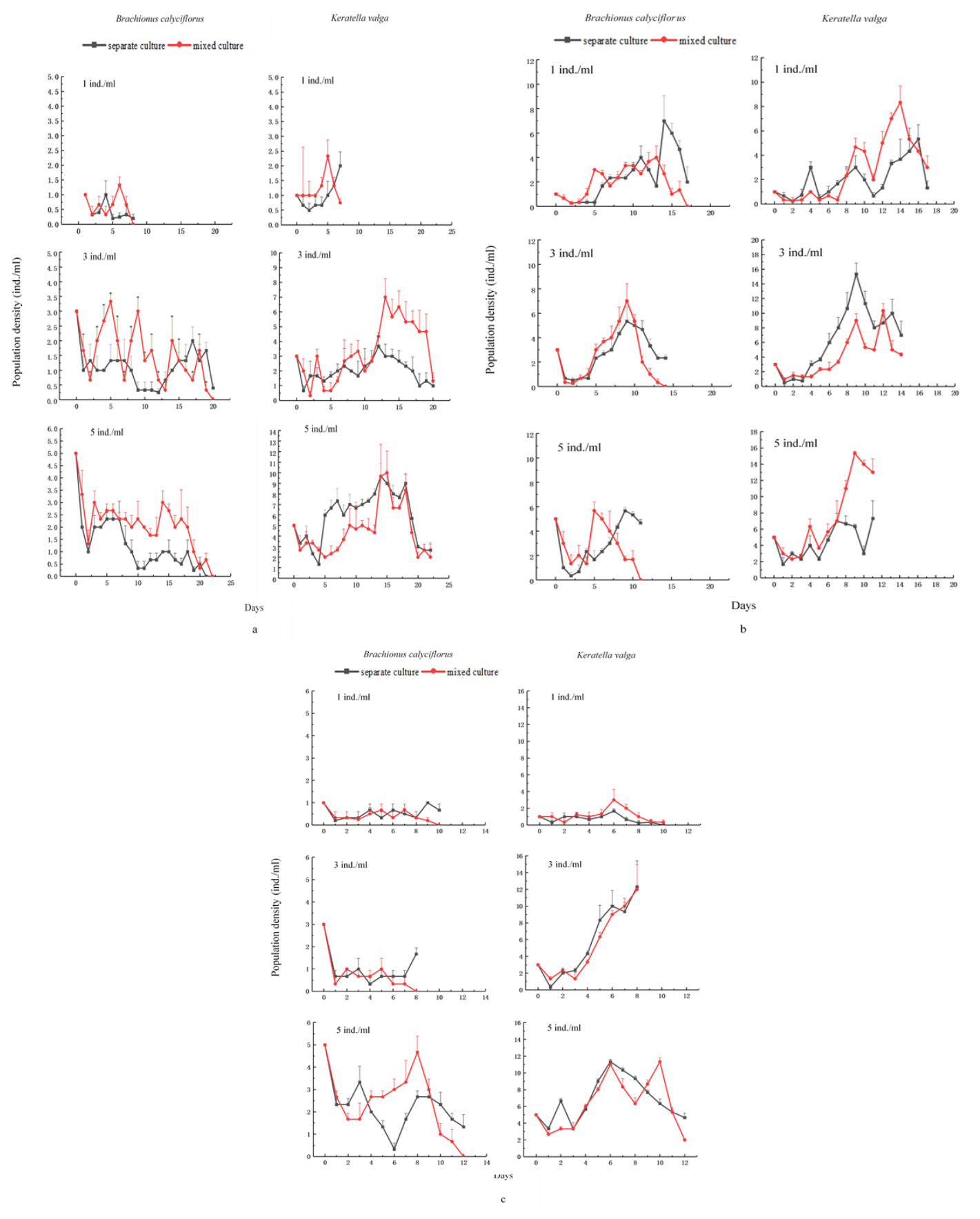

Figure 4. Population growth of B. calyciflorus and $K$. valga in separate and mixed cultures at different initial densities (mean \pm standard errors) $\left(\right.$ a. $20^{\circ} \mathrm{C}$; b. $25{ }^{\circ} \mathrm{C}$; c. $30^{\circ} \mathrm{C}$ )

The population growth rates of $B$. calyciflorus and $K$. valga at different temperatures and initial densities in separate and mixed cultures are shown in Figure 5a. At any temperature, the population growth rate of $K$. valga in mixed cultures decreased with increasing initial density. Regardless of initial density, $K$. valga suppressed the 
population growth rate of $\mathrm{B}$. calyciflorus at $20^{\circ} \mathrm{C}$ and $25^{\circ} \mathrm{C}$; and $\mathrm{B}$. calyciflorus suppressed that of $K$. valga at $25^{\circ} \mathrm{C}$ and $30^{\circ} \mathrm{C}$. Overall, competition had an inhibitory effect on the population growth rates of both rotifer species in mixed cultures at $25^{\circ} \mathrm{C}$.

The maximum population densities of $B$. calyciflorus and $K$. valga at different temperatures and food concentrations in separate and mixed cultures are shown in Figure $5 b$. Regardless of competition, the maximum population densities of both rotifer species increased with increasing initial density in separate and mixed cultures at $20{ }^{\circ} \mathrm{C}$ and $30^{\circ} \mathrm{C}$. Regardless of initial density, interspecific competition had no significant effect on the maximum population densities of both rotifer species in mixed cultures at $20{ }^{\circ} \mathrm{C}$ and $30{ }^{\circ} \mathrm{C}$.
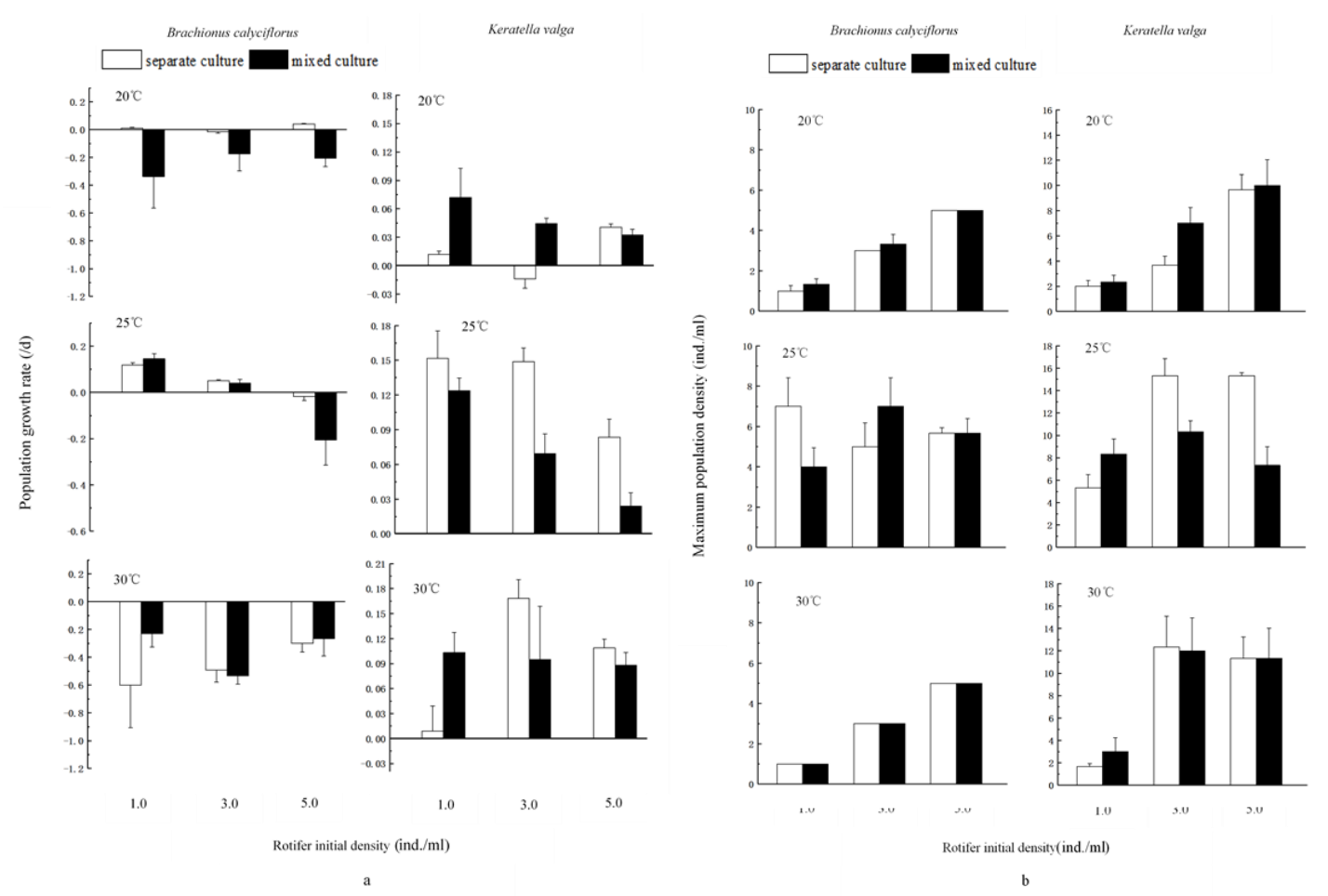

Figure 5. Population growth rates (a) and maximum population densities (b) of B. calyciflorus and $K$. valga in separate and mixed cultures at different temperatures and food concentrations (mean \pm standard errors)

\section{Outcome of competition between $B$. calyciflorus and $K$. valga at different food concentrations and initial densities}

The population growth dynamics and outcome of competition between $B$. calyciflorus and $K$. valga at different food concentrations and initial densities are shown in Figure 6.

In general, regardless of competition, the population densities of both B. calyciflorus and $K$. valga increased with increasing food concentration, but did not change significantly with increasing initial density.

Interspecific competition inhibited the population density growth of both species, leading to lower population densities of both species in mixed cultures than in separate cultures. However, the population densities were higher in mixed cultures than in separate cultures at the lowest initial density. Regardless of initial density, $B$. calyciflorus was competitively excluded by $K$. valga at lower food concentrations $(0.5 \times$ 
$10^{6}$ and $1.0 \times 10^{6}$ cells $\left./ \mathrm{mL}\right)$. At the highest food concentration $\left(3.0 \times 10^{6}\right.$ cells $\left./ \mathrm{mL}\right), K$. valga was competitively excluded by B. calyciflorus; and the duration of competitive exclusion was not significantly related to initial density or food concentration.
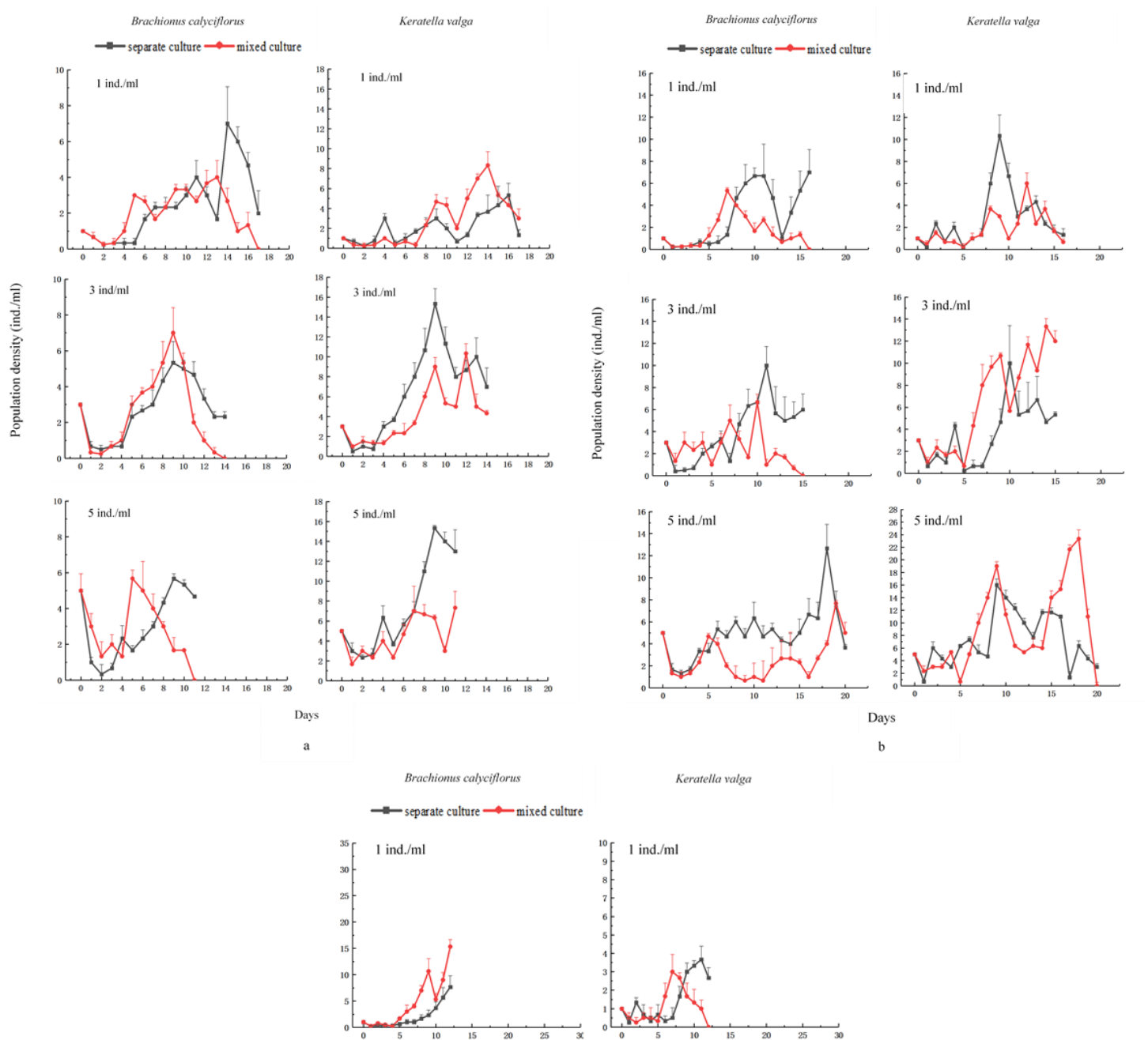

Keratella valga
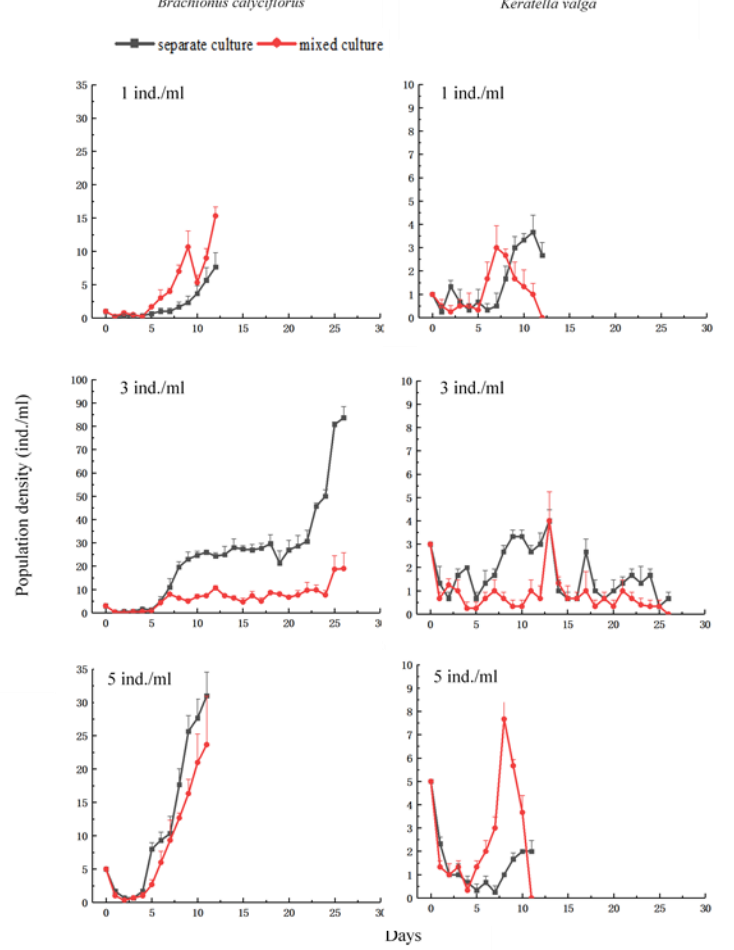

Figure 6. Population growth of B. calyciflorus and $K$. valga in separate and mixed cultures at different initial densities (mean \pm standard errors) ( a. food concentration $=0.5 \times 10^{6} \mathrm{cell} / \mathrm{s} / \mathrm{mL}$; b. food concentration $=1.0 \times 10^{6}$ cells $/ \mathrm{mL} ; \mathrm{c}$. food concentration $\left.=3.0 \times 10^{6} \mathrm{cells} / \mathrm{mL}\right)$ 
The three-way analysis of variance showed that food concentration and initial density had a significant effect on the population growth rate of B. calyciflorus, and that food concentration, initial density, competition with $K$. valga, and their interactions had a significant effect on the maximum population density of $B$. calyciflorus $(p<0.05)$. Food concentration, initial density, competition with $B$. calyciflorus, and their interactions had a significant effect on the population growth rate of $K$. valga $(p<0.05)$. All the factors had no significant effect on the maximum population density of $K$. valga $(p<0.05)($ Table 5).

Table 5. Three-way analysis of variance of population growth rates and maximum population densities of B. calyciflorus and $K$. valga ( $p$-value)

\begin{tabular}{c|c|c|c|c|c|c|c|c}
\hline Competitor & Parameter & $\mathbf{F}$ & $\mathbf{I}$ & $\mathbf{C}$ & $\mathbf{T}^{*} \mathbf{I}$ & $\mathbf{T}^{*} \mathbf{C}$ & $\mathbf{I}^{*} \mathbf{C}$ & $\mathbf{T}^{*} \mathbf{I}^{*} \mathbf{C}$ \\
\hline \multirow{2}{*}{ B. calyciflorus } & Population growth rate & $\mathbf{0 . 0 4 5}$ & $\mathbf{0 . 0 2 6}$ & 0.180 & 0.081 & 0.924 & 0.388 & 0.586 \\
& Maximum population density & $p<0.01$ & $p<0.01$ & $p<0.01$ & $p<0.01$ & $p<0.01$ & $\mathbf{0 . 0 1 9}$ & $p<0.01$ \\
\hline \multirow{2}{*}{ K. valga } & Population growth rate & $p<0.01$ & $p<0.01$ & 0.428 & 0.124 & 0.114 & $\mathbf{0 . 0 4 7}$ & $\mathbf{0 . 0 3 0}$ \\
& Maximum population density & 0.434 & 0.658 & 0.622 & 0.829 & 0.508 & 0.891 & 0.681 \\
\hline
\end{tabular}

F: food concentration, I: initial density, C: competition, T: temperature

Regardless of food concentration and initial density, both $B$. calyciflorus and $K$. valga were inhibited by competition with each other, resulting in a significant decrease in their population growth rates. The maximum population density of $B$. calyciflorus also decreased, whereas that of $K$. valga slightly increased (Table 5; Fig. 7).
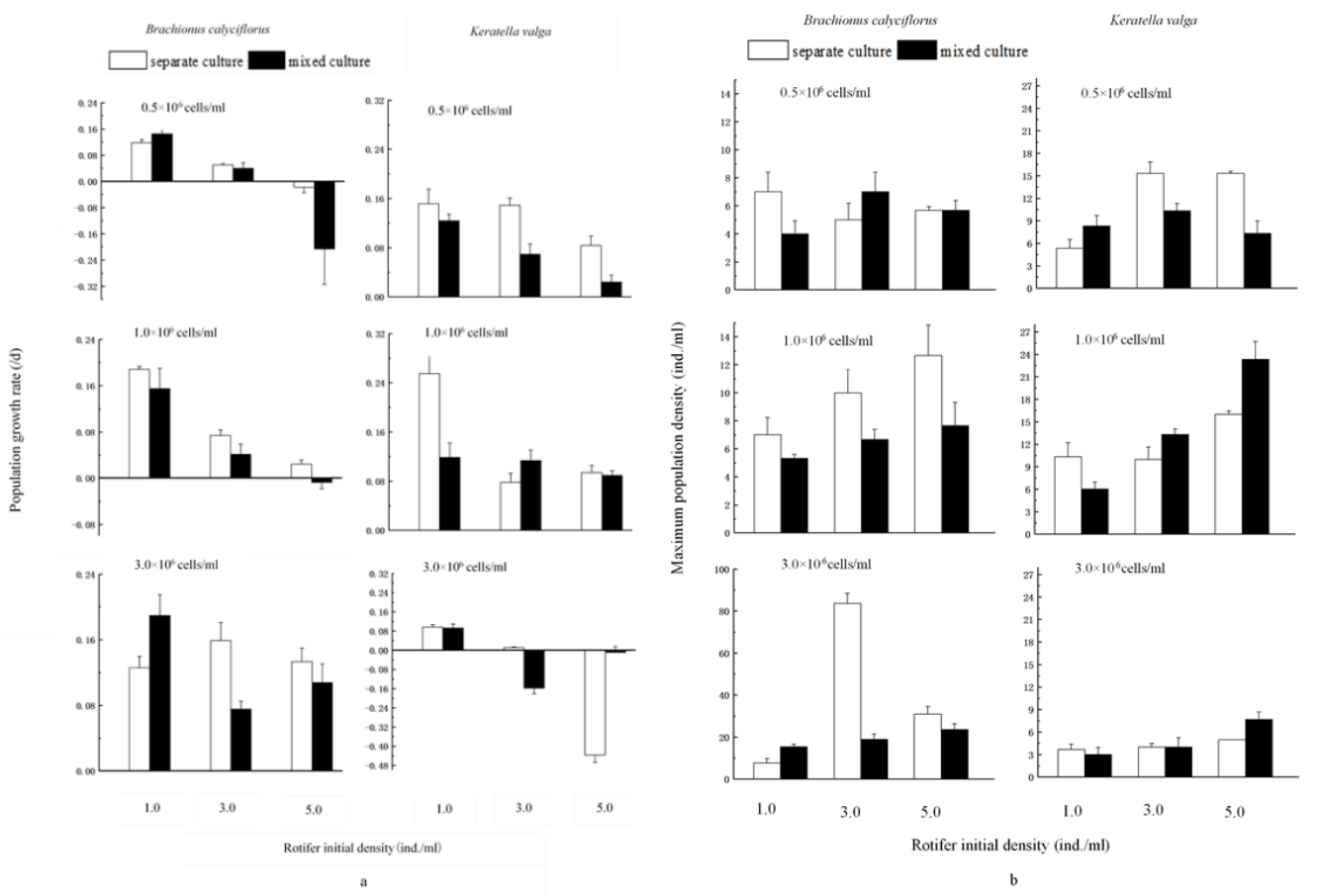

Figure 7. Population growth rates (a) and maximum population densities (b) of B. calyciflorus and $K$. valga in separate and mixed cultures at different food concentrations and initial densities (mean \pm standard errors) 
The population growth rates of B. calyciflorus and $K$. valga at different temperatures and food concentrations in separate and mixed cultures are shown in Figure $7 a$. Regardless of competition, the population growth rate of $B$. calyciflorus increased with increasing food concentration $(p<0.05)$ and decreased with increasing initial density $(p<0.05)$, whereas that of $K$. valga decreased with both increasing food concentration and initial density $(p<0.01)$. At any initial density, competition with $K$. valga inhibited the population growth of $B$. calyciflorus at low and medium food concentrations $(0.5 \times$ $10^{6}$ and $1.0 \times 10^{6}$ cells $/ \mathrm{mL}$ ), resulting in a significant decrease in the population growth rate of $B$. calyciflorus.

The maximum population densities of $B$. calyciflorus and $K$. valga at different temperatures and food concentrations in separate and mixed cultures are shown in Figure $7 b$. Regardless of competition, the maximum population density of $B$. calyciflorus significantly increased with both increasing food concentration and initial density $(p<0.01)$. Similarly, the maximum population density of $K$. valga slightly increased with both increasing food concentration and initial density. Regardless of food concentration and initial density, competition with $K$. valga inhibited the population growth of $B$. calyciflorus, leading to a decrease in the maximum population density of $B$. calyciflorus.

\section{Discussion}

The population structure and population dynamics of zooplankton in natural water are mainly caused by the influence of many environmental factors. The interspecific competition of rotifers is mainly chemical interference competition and resource utilization competition, without mechanical interference (Rothhaupt, 1988). Therefore, the competition between $B$. calyciflorus and $K$. valga is mainly chemical interference competition and resource utilization competition. Combined with the above analysis, it is easy to know that temperature and food concentration are the main factors affecting the interspecific competition between the two rotifers. Generally, the population growth of rotifers will increase with the increase of temperature and food concentration within the range of temperature and food concentration for rotifers to adapt to survival (Kauler and Enesco, 2011). In general, B. calyciflorus and $K$. valga in single culture or mixed culture conform to the law of population dynamics, and the experimental duration will shorten with the increase of temperature. However, because the intrinsic growth rate of $K$. valga is the largest at $25^{\circ} \mathrm{C}$ and decreased at $20^{\circ} \mathrm{Cand} 30^{\circ} \mathrm{C}$, the most suitable water temperature is about $25^{\circ} \mathrm{C}$ according to the life history parameters such as average life span, oviposition and net reproductive rate of $K$. valga. Therefore, with the increase of experimental temperature $\left(20^{\circ} \mathrm{C}, 25^{\circ} \mathrm{C}\right.$ and $\left.30^{\circ} \mathrm{C}\right)$, the population growth in the single culture and competition groups showed an increasing or decreasing trend. In addition to the factors of temperature and food concentration, the initial density of rotifer also had a great influence on the population growth dynamics of B. calyciflorus. In the early stage of the experiment, the population density of rotifer increased with the increase of initial density. With the extension of culture time, the difference caused by initial density changed irregularly. The results of this experiment are roughly the same ( $\mathrm{Xi}$ and Huang, 2000).

The critical food density, individual size and hunger tolerance of the two rotifers also play an important role in the outcome of the competition. Among them, in terms of the impact of the relative size of competitors on the outcome of competition, B. calyciflorus 
is larger than $K$. valga under the comparison of individual size, and both are phytophagous zooplankton. Larger zooplankton consume less energy when swimming and are dominant in population competition, but the larger the individual is, the greater the energy required for its own metabolism. Therefore, B. calyciflorus may have an advantage in interspecific competition at high food concentration, which is opposite at low food concentration. In the mixed culture group, regardless of the initial density of rotifers, at low and medium food concentrations $\left(0.5\right.$ and $1.0 \times 10^{6}$ cells $\left./ \mathrm{ml}\right), K$. valga rejected rotifer B. calyciflorus, but the food concentration was high $\left(3.0 \times 10^{6}\right.$ cells $\left./ \mathrm{ml}\right)$, B. calyciflorus rejected $K$. valga.

The effect of single factor on interspecific competition of rotifer is more regular, while the effect of the interaction of two or more factors on interspecific competition may be more complex. Some studies have shown that the interspecific competition results of B. calyciflorus (large size) and Anuraeopsis fissa (small size) are jointly determined by rotifer size, food concentration and rotifer inoculation density (Sarma et al., 1996), which shows that multiple factors and their interactions jointly affect the competition outcome. After the research of this experiment, it can be further discussed.

Under the same mixed culture condition at $25^{\circ} \mathrm{C}$, regardless of the initial density of rotifers, at low and medium food concentrations $\left(0.5\right.$ and $1.0 \times 10^{6}$ cells $/ \mathrm{ml}$ competition group, most of $K$. valga rejected $B$. calyciflorus, while the food concentration was high $\left(3.0 \times 10^{6}\right.$ cells $/ \mathrm{ml}, B$. calyciflorus rejected $K$. valga, but at medium food concentration $\left(1.0 \times 10^{6}\right.$ cells $\left./ \mathrm{ml}\right)$, when the initial density of rotifer increased to 5 ind. $/ \mathrm{ml}, B$. calyciflorus rejected $K$. valga on the contrary. Regardless of the initial density of rotifer, the population growth rate of rotifer B. calyciflorus was mostly positive, while $K$. valga has positive growth at low and medium food concentrations $\left(0.5\right.$ and $1.0 \times 10^{6}$ cells $\left./ \mathrm{ml}\right)$ and has negative growth mostly at high food concentration $\left(3.0 \times 10^{6}\right.$ cells $\left./ \mathrm{ml}\right)$.

This part of the experiment can also show that food concentration is the main factor affecting interspecific competition. We find that at the temperature of $25^{\circ} \mathrm{C}$, the food concentration of $1.0 \times 10^{6}$ cells $/ \mathrm{ml}$ and the initial density of $1,3 \mathrm{ind} . / \mathrm{ml}, K$. valga repels B. calyciflorus. When the initial density increases to $5 \mathrm{ind} . / \mathrm{ml}$, the competition result is opposite, which also obtains the effect of the initial density on the interspecific competition of rotifer. Of course, this part of the experimental results also depends on temperature, food concentration, initial density and their interaction.

\section{Conclusion}

This study investigated the interspecific competition between B. calyciflorus and $K$. valga under pairwise combinations of temperature, food concentration, and initial density. The following conclusions have been reached:

First, in separate cultures, the population growth of both B. calyciflorus and $K$. valga was affected by temperature and food concentration. The population growth rates and maximum population densities of both rotifer species were higher at $30^{\circ} \mathrm{C}$ than at $20{ }^{\circ} \mathrm{C}$ and $25^{\circ} \mathrm{C}$. The population growth rate and maximum population density of $B$. calyciflorus increased overall with increasing food concentration, whereas the opposite was found for K. valga. The initial density had no obvious effect on B. calyciflorus. The population growth rate of $K$. valga decreased with increasing initial density, leading to a slight increase in maximum population density.

Second, in mixed cultures, B. calyciflorus was significantly inhibited by competition with $K$. valga, leading to an overall decrease in the population growth rate and 
maximum population density of B. calyciflorus. Similarly, K. valga was also affected by competition with $B$. calyciflorus. However, the population growth rate and maximum population density of $K$. valga increased under some of the experimental conditions (at a temperature of $20^{\circ} \mathrm{C}$ or an initial density of $1.0 \times 10^{6}$ cells $/ \mathrm{mL}$ ) and decreased under others.

Third, the outcome of the interspecific competition between $B$. calyciflorus and $K$. valga was mainly affected by food concentration. B. calyciflorus was excluded by $K$. valga at low and medium food concentrations $\left(0.5 \times 10^{6}\right.$ and $1.0 \times 10^{6}$ cells $\left./ \mathrm{mL}\right)$, whereas the opposite was found at high food concentration $\left(3.0 \times 10^{6}\right.$ cells $\left./ \mathrm{mL}\right)$. Moreover, the combination of $20^{\circ} \mathrm{C}$, a food concentration of $3.0 \times 10^{6}$ cells $/ \mathrm{mL}$, and an initial density of 3 ind. $/ \mathrm{mL}$ and that of $25^{\circ} \mathrm{C}, 1.0 \times 10^{6}$ cells $/ \mathrm{mL}$, and 5 ind. $/ \mathrm{mL}$ yielded opposite outcomes of competition. Temperature, initial density, and interactions between the three factors also had non-negligible effects on the outcome of the competition between B. calyciflorus and $K$. valga.

Finally, although we have made some achievements in the research on the interspecific competition and mechanism of the two rotifers, there are still many areas that need to be improved, including increasing the types of competitive species, which is closer to the actual situation of interspecific competition of rotifers in natural water. It is necessary to increase the types of influencing factors, because the predation pressure in natural water and the stress of environmental pollutants also have a great impact on the interspecific competition of rotifers. By studying the interspecific competition of rotifers and analyzing the influencing factors, we can build a competition model to simulate, predict and analyze the interspecific competition outcome under various competition conditions.

Acknowledgements. This work was supported by Guangdong Basic and Applied Basic Research Foundation (No. 2018A030313848), National Key R\&D Program of China on "Blue Granary Technology Innovation" (No. 2018YFD0900802), and Central Public-interest Scientific Institution Basal Research Fund of Chinese Academy of Fishery Sciences (No. 2021SJ-TD1).

\section{REFERENCES}

[1] Aoyagui, A. S. M., Bonecker, C. (2005): Relationships between rotifers, phytoplankton and bacterioplankton in the Corumba reservoir, Goias State, Brazil. - Hydrobiologia 546: 415-421.

[2] Arora, J., Mehra, N. K. (2003): Seasonal dynamics of rotifers in relation to physical and chemical conditions of the river Yamurna (Delhi), India. - Hydrobiologia 491: 101-109.

[3] Benincà, E., Dakos, V., Nes, E., Huisman, J., Scheffer, M. (2011): Resonance of plankton communities with temperature fluctuations. - American Naturalist 178: 87-95.

[4] Devetter, M. (1998): Influence of environmental factors on the rotifer assemblages in an artificial lake. - Hydrobiologia 387/388: 171-178.

[5] Divya, S. P., Kathiresan, K., Asha, P., Sekar, V., Rajasekaran, R. (2012): Experimental study of the interspecific competition between two sibling marine herbivorous rotifers in relation to food availability and initial population density. - Acta Oceanol Sin 31: 113126.

[6] Dong, L., Xi, Y., Liu, G., Chen, F., Ge, Y., Wen, X. (2004): Effect of temperature and food concentration on the population dynamics of three Brachionus calyciflorus strains. Chinese Journal of Applied Ecology 15(11): 2165-2169. 
[7] Dumont, H., Sarma, S., Ali, A. (1995): Laboratory studies on the population dynamics of Anuraeopsis fissa (Rotifera) in relation to food density. - Freshwater Biology 33: 39-46.

[8] Elser, J., Hayakawa, K., Urabe, J. (2001): Nutrient limitation reduces food quality for zooplankton: Daphnia response to seston phosphorus enrichment. - Ecology 82: 898-903.

[9] Espinosa-Rodríguez, C., Sarma, S., Nandini, S. (2012): Interactions between the rotifer Euchlanis dilatata and the cladocerans Alona glabra and Macrothrix triserialis in relation to diet type. - Limnologica 42: 50-55.

[10] Feniova, I., Razlutsky, V., Palash, A. (2011): Temperature effects of interspecies competition between cladoceran species in experimental conditions. - Inland Water Biology 4: 65-71.

[11] Fernández-Araiza, M. A., Sarma, S. S. S., Nandini, S. (2005): Combined effects of food concentration and temperature on competition among four species of Brachionus (Rotifera). - Hydrobiologia 546: 519-534.

[12] Ferrao-Filho, A., Arcifa, M., Fileto, C. (2003): Resource limitation and food quality for cladocerans in a tropical Brazilian lake. - Hydrobiologia 491: 201-210.

[13] Herzig, A. (1987): The analysis of planktonic rotifer populations: plea for long-term investigations. - Hydrobiologia 14: 163-180.

[14] Huang, X., Hu, C., Wu, Z. (1985): Rotifers in lake Donghu, Wuhan. - Acta Hydrobiologica Sinica 9(2): 129-143.

[15] Karabin, A., Ejsmont-Karabin, J. (2005): An evidence for vertical migrations of small rotifers-a case of rotifer community in a dystrophic lake. - Hydrobiologia 546: 381-386.

[16] Kauler, P., Enesco, H. E. (2011): The effect of temperature on life history parameters and cost of reproduction in the rotifer Brachionus calyciflorus. - Journal of Freshwater Ecology 26: 399-408.

[17] Li, C., Niu, C. (2015): Effects of sexual reproduction of the inferior competitor Brachionus calyciflorus on its fitness against Brachionus angularis. - Chin J Oceanol Limnol 33: 356-363.

[18] Lin, Q., Zhao, S., Han, B. (2005): Rotifer distribution in tropical reservoirs, Guangdong Province, China. - Acta Ecologica Sinica 25(5): 1123-1131.

[19] Ma, R., Niu, C., Bao, L., Lu, F. (2004): Effects of algal food concentration on developmental periods and population growth of the rotifer Brachionus quadridentatus. Acta Zoologica Sinica 50(5): 753-758.

[20] May, L. (1983): Rotifer occurrence in relation to water temperature in Leven, Scotland. Hydrobiologia 104: 311-315.

[21] Montero-Pau, J., Serra, M. (2011): Life-cycle switching and coexistence of species with no niche differentiation. - PLoS One 6: e20314.

[22] Persson, J., Vrede, T., Holmgren, S. (2008): Responses in zooplankton populations to food quality and quantity changes after whole lake nutrient enrichment of an oligotrophic subalpine reservoir. - Aquatic Sciences 70: 142-155.

[23] Rebolledo, A. U., Nandini, S., Sarma, S. S. S., Reyes, C. R. J., de Oca, A. R. M. G. (2018): Demographic and competition studies on Brachionus ibericus and Proales similis in relation to salinity and algal (Nannochloropsis oculata) density. - Aquacult Int 26: 629-644.

[24] Rothhaupt, K. O. (1988): Mechanisitic resource competition theory applied to laboratory experiments with zooplankton. - Nature 333: 660-662.

[25] Rothhaupt, K. O. (1990): Resource competition of herbivorous zooplankton: a review of approaches and perspectives. - Arch Hydrobiol 118: 1-29.

[26] Ruttner-Kolisko, A. (1974): Planktonic rotifers: biology and taxonomy. - Die Binnengewasser 26(Suppl 1): 1-146.

[27] Sarma, S. S. S., Nandini, S. (2002): Comparative life table demography and population growth of Brachionus macracanthus Daday, 1905 and Platyias quadricornis Ehrenberg, 1832 (Rotifera, Brachionidae) in relation to algal (Chlorella vulgaris) food density. Acta Hydrochim Hydrobiol 30: 128-140. 
[28] Sarma, S. S. S., Iyer, N., Dumont, H. J. (1996): Competitive interactions between herbivorous rotifers: importance of food concentration and initial population density. Hydrobiologia 331(1-3): 1-7.

[29] Sarma, S. S. S., Rivera, S. A., Hinojosa, F. E. (2007): Combined influence of food level and inoculation density on competition between Anuraeopsis fissa and Brachionus patulus or Brachionus macracanthus (Rotifera: Brachionidae). - Russ J Ecol 38: 353362.

[30] Stanier, R. (1971): Purification and properties of unicellular blue-green algae (order Chroococcales). - Bacteriological Reviews 35.

[31] Stemberger, R., Gilbert, J. (1985): Assessment of threshold food levels and populations growth in planktonic rotifers. - Archive für Hydrobiologie Beiheft 21: 269-275.

[32] Stemberger, R., Gilbert, J. (1987): Rotifer threshold food concentrations and the sizeefficiency hypothesis. - Ecology 68: 181-187.

[33] Sterner, R., Hessen, D. (1994): Algal nutrient limitation and the nutrition of aquatic herbivores. - Annual Review of Ecology and Systematics 25: 1-29.

[34] Tian, B., Ding, Q., Li, Y. (2009): Effects of initial population, food quantities and temperature on population growth of Brachionus calyciflorus. - Journal of Chongqing Normal University (Natural Science) 26(1): 26-29.

[35] U.S. EPA. (1985): Methods for Measuring the Acute Toxicity of Effluents to Freshwater and Marine Organisms. - In: Peltier, W. H., Weber, C. I. (eds.) EPA/600/4-85/013, 216. U.S. Environment Protect Agency, Washington, D.C.

[36] Van Dijk, G., Van Zanten, B. (1995): Seasonal changes in zooplankton abundance in the lower Rhine during 1987-1991. - Hydrobiologia 304: 29-38.

[37] Wang, J. (1995): Effects of ecological factors on the population dynamic of brachionus calyciflorus-The effect of temperature and food density. - Transactions of Oceanology and Limnology 4: 21-27.

[38] Wang, M., Xi, Y., Zhou, B., Zhang, Y. (2014): Adaptation of brachionus calyciflorus (Rotifera) from lake Jinghu an summer to water temperature: population growth experiment study. - Acta Hydrobiologica Sinica 38(6): 1017-1023.

[39] Wen, X., Xi, Y., Zhang, L., Lu, X., Chen, F. (2004): Community structure and species diversity of rotifers in the Wuhu section of the Qingyi River. - Biodiversity Science 12(4): 387-395.

[40] Xi, Y., Huang, X. (2000a): Effect of initial population density on resting egg formation of rotifer Brachionus calyciflorus. - Chinese Journal of Applied Ecology 11(2): 273-276.

[41] Yoshida, T., Urabe, J., Elser, J. (2003): Assessment of "top-down" and "bottom-up" forces as determinants of rotifer distribution among lakes in Ontario, Canada. Ecological Research 18: 639-650.

[42] Zhang, Y., Xie, Y., Hu, J., Lin, J., Hu, S. (2005): Effects of Food and Initial Population Density on Population Growth of Brachionus plicatilis. - Journal of Jimei University 10(1): 1-7.

[43] Zhang, K., Wan, Q., Xi, Y. L. (2019): Competition between Brachionus calyciflorus and Brachionus angularis (Rotifera) in relation to algal food level and initial population density. - Annales de Limnologie-International Journal of Limnology 55: 2. 